\title{
Short communication: Phenotypic and genetic diversity of wild Lactococcus lactis isolated from traditional Pecorino cheeses of Tuscany
}

\author{
B. Turchi, ${ }^{*}$ M. L. Van Tassell,† A. Lee,† R. Nuvoloni, ${ }^{*}$ D. Cerri, ${ }^{*}$ and M. J. Millert ${ }^{1}$ \\ *Dipartimento di Patologia Animale, Profilassi ed Igiene degli Alimenti, Università di Pisa, Viale delle Piagge 2, 56124, Pisa, Italy \\ †Department of Food Science and Human Nutrition, University of Illinois, 905 S Goodwin Ave., Urbana 61801
}

\begin{abstract}
Wild Lactococcus lactis isolates from traditional Pecorino cheeses in 4 regions of Tuscany were isolated and characterized to evaluate the diversity of autochthonous lactococci. Sixty strains of Lactococcus were clustered by the results of carbohydrate utilization and diagnostic enzyme activity. Twenty-one unique strains were then chosen for characterization of salt and temperature tolerance, as well as acidification and proteolytic activity in milk. Genetic analysis of these strains was performed via $16 \mathrm{~S}$ ribosomal DNA sequencing and multilocus sequence typing (MLST) to elucidate diversity relative to their location of origin. Phylogenetic analysis showed distinct clustering by region within organism subspecies, and phenotypic properties demonstrated concomitant trends. Multilocus sequence typing thus allowed for the regional distinction of isolates separate from those of previous works, supporting the concept that distinctive regional qualities of cheeses are strongly influenced by microbial ecology.
\end{abstract}

Key words: Lactococcus lactis, Pecorino cheese, multilocus sequence typing, microbial ecology

\section{Short Communication}

Pecorino is a ewe milk cheese that is very popular throughout Italy and an important export. Traditional Pecorino cheeses are produced using artisanal methods of production, storage, and aging that are consistent with continuous production in a given territory for no less than 25 yr (Decreto Legislativo n.173, 30th April, 1998). Pecorino cheeses are thereby regionally unique and may lose characteristic attributes if produced similarly in other areas. This specificity is partly related to the breed and diet of dairy animals, which determine the physical and chemical properties of the raw milk (Palmquist et al., 1993), and partly to variations in cheese-making practices. Microbiological aspects are

Received December 21, 2012.

Accepted February 13, 2013.

${ }^{1}$ Corresponding author: mille216@illinois.edu also important, because traditional Pecorino is made by first fermenting raw milk at room temperature to enrich its microbial load, which can vary significantly by location. The resulting products maintain regionally distinct characteristics reflective of these unique autochthonous microbiota.

Lactococcus lactis is the primary constituent of many industrial and artisanal starter cultures used to ferment dairy products (Smit et al., 2005) and is a naturally dominant species within many sheep milk cheeses. The microbiota of ewe milk and its cheeses have been variously quantified before, showing a high prevalence of lactococci, often among similarly high or higher levels of enterococci and lactobacilli (Durlu-Ozkaya et al., 2001; Medina et al., 2001; Feutry et al., 2012). More recent next-generation sequencing approaches that avoid the selectivity pitfalls of culture-dependent isolation and enumeration show that lactococci may actually be heavily dominant in raw ewes' milk cheeses (Alegría et al., 2012; Quigley et al., 2012). The microbial characterization of cheeses, especially those with protected designations of origin, has been of increasing interest as the allure of preserving natural microbiota has grown. Pecorino cheeses from several regions of Italy have been profiled for autochthonous microorganisms (Mannu and Paba, 2002; Randazzo et al., 2006; Aquilanti et al., 2007), and the focus has often been on nonstarter lactic acid bacteria for their role in ripening and flavor development (De Angelis et al., 2001; Randazzo et al., 2008). Yeasts, Enterobacteriaceae, and pathogens have also been targeted (Cosentino et al., 2001; Chaves-López et al., 2006; Gardini et al., 2006; Giammanco et al., 2011). However, little is known of lactococcal diversity, distribution, or regional variability in Pecorino cheeses.

Multilocus sequence typing (MLST), the sequence analysis of genes coding for housekeeping and functional proteins, is being used increasingly for the precise characterization of nonpathogenic food bacteria such as Lactobacillus spp. (Cai et al., 2007; Diancourt et al., 2007; Tanganurat et al., 2009), Oenococcus oeni (de Las Rivas et al., 2004; Bilhère et al., 2009), and Lactococcus lactis (Rademaker et al., 2007; Fernández et al., 2011). Multilocus sequence typing is straightforward, unam- 
biguous, scalable, and highly discriminatory compared with most fingerprinting methods. Sequence data are easily reproducible, provide a measure of evolutionary analysis, and are portable between laboratories for comparison, making MLST ideal for measuring ecological diversity. In the present study, wild Lactococcus isolates from traditional Pecorino cheeses made in different provinces of Tuscany (Pisa, Pistoia, Siena, and MassaCarrara) were isolated and select strains were chosen for evaluation via MLST and traditional phenotypic and technological differentiation to help illustrate the regional diversity of $L$. lactis in Tuscan Pecorino cheese

Pecorino cheeses were sampled from one dairy in each of 4 regions in Tuscany (Table 1 ). The cheeses were made with fresh raw ewe milk fermented by autochthonous microbes, without any addition of starter culture. Isolation was performed following the procedure described by IDF (1988). Organisms were isolated on M17 agar with 10\% lactose (Oxoid, Basingstoke, UK) for each sampling time point: from the milk, curd, and after 2, $7,14,21,28,35,42$, and $60 \mathrm{~d}$ of ripening. Eight isolates from each sampling point were selected and streaked out 3 times on the same agar medium to purify. In total, 320 isolates were obtained from 4 dairies. Of these isolates, 60 were presumptively identified as lactococci based on Gram staining, catalase, oxidase, and hemolytic activity (Bergey and Holt, 1994). Carbohydrate fermentation and enzymatic patterns were determined for these 60 isolates using the API 20 Strep system (API System, bioMérieux, Marcy l'Etoile, France) following the manufacturer's recommendations (Supplementary Table S1; http://www.journalofdairyscience.org/). The isolates were grouped via single-linkage cluster analysis performed with distances calculated from API 20 test results using Mesquite v2.75 (Maddison and Maddison, 2011), and representative isolates were selected from each of the major clades, resulting in a total of 21 isolates, including 3 to 7 isolates from each dairy (Figure 1). Lactococcus lactis ssp. lactis ATCC19435 and L. lactis ssp. cremoris ATCC 19257 were used as controls for salt and temperature tolerance testing and for genetic characterization. The sources and sampling times of the 21 isolates are outlined in Table 1 . Analyses were carried out in triplicate.

The ability of the isolates $(\mathrm{n}=21)$ to grow in different salt concentrations $(2,3,4,5,6$, and $6.5 \% \mathrm{wt} /$ vol) at $30^{\circ} \mathrm{C}$ and at different temperatures $(40,43$, and $45^{\circ} \mathrm{C}$ ) was tested in sterile M17 medium and measured for blank-corrected change in optical density at $600 \mathrm{~nm}$ $\left(\Delta \mathbf{O D}_{600}\right)$ after $24 \mathrm{~h}$ of incubation using a Spectronic 21 spectrophotometer (Figure 2; Bausch and Lomb, Rochester, NY). All isolates grew very well $\left(\Delta \mathrm{OD}_{600}\right.$ $\geq 1.0)$ at $40^{\circ} \mathrm{C}$ and fairly well $\left(\Delta \mathrm{OD}_{600} \geq 0.5\right)$ at $43^{\circ} \mathrm{C}$. Almost all grew well in a $4 \%$ salt medium as well. Both temperature and salt tolerance at these levels are classically attributed only to L. lactis ssp. lactis (Bergey and Holt, 1994). Some isolates even grew at $45^{\circ} \mathrm{C}$ and in the presence of up to $6 \%$ salt.

Acidification and proteolytic activities of selected strains were evaluated as previously described in Turchi et al. (2011). In short, isolates were inoculated (1\% $\mathrm{vol} / \mathrm{vol}$ ) into skim milk reconstituted from powder (Oxoid) and incubated at $30^{\circ} \mathrm{C}$. Changes in acidity were recorded as decreases in $\mathrm{pH}$ from that of uninoculated milk (pH 6.76) after 6 and 24 h. Proteolytic activities were detected spectrophotometrically at $340 \mathrm{~nm}$ after $48 \mathrm{~h}$ with o-phthaldialdehyde. Proteolytic activity of the bacterial isolates was expressed as micrograms of glycine per milliliter using a standard curve of glycine (BDH Chemicals Ltd., Poole, UK). The selected strains varied widely in the acidification and proteolysis of milk (Figure 2). The strains showing a greater decrease in $\mathrm{pH}$ at $6 \mathrm{~h}$ also generally demonstrated the greatest acidification after $24 \mathrm{~h}$. Proteolytic activities showed trends similar to those of acidification, with the more acidifying isolates generally demonstrating greater proteolysis.

To identify the subspecies of the 21 chosen isolates, total chromosomal $\mathrm{DN}=\mathrm{A}$ was extracted from each isolate by using the DNeasy Tissue kit (Qiagen GmbH, Hilden, Germany) according to the supplier's procedures. Primers 8F and 1391R from Palmer et al. (2006) were used for amplifying bacterial 16S ribosomal

Table 1. Source (region) and ripening time of Lactococcus isolates characterized

\begin{tabular}{llc}
\hline Strain ID & Region & $\begin{array}{c}\text { Ripening } \\
\text { time }(\mathrm{d})\end{array}$ \\
\hline Lc1 & Siena & 42 \\
Lc2 & Siena & 14 \\
Lc3 & Siena & 14 \\
Lc4 & Siena & 28 \\
Lc5 & Siena & (curd) \\
Lc6 & Siena & (milk) \\
Lc7 & Siena & 72 \\
Lc8 & Pistoia & 7 \\
Lc9 & Pistoia & 7 \\
Lc10 & Pistoia & 7 \\
Lc11 & Pistoia & 14 \\
Lc12 & Pistoia & 28 \\
Lc13 & Massa-Carrara & 29 \\
Lc14 & Massa-Carrara & 30 \\
Lc15 & Massa-Carrara & 7 \\
Lc16 & Pisa & 7 \\
Lc17 & Pisa & 7 \\
Lc18 & Pisa & 7 \\
Lc19 & Pisa & 2 \\
Lc20 & Pisa & 2 \\
Lc21 & Pisa & NA \\
ATCC 19435 & NA ${ }^{1}$ & NA \\
ATCC 19257 & NA & \\
\hline
\end{tabular}

${ }^{1}$ Not applicable. 


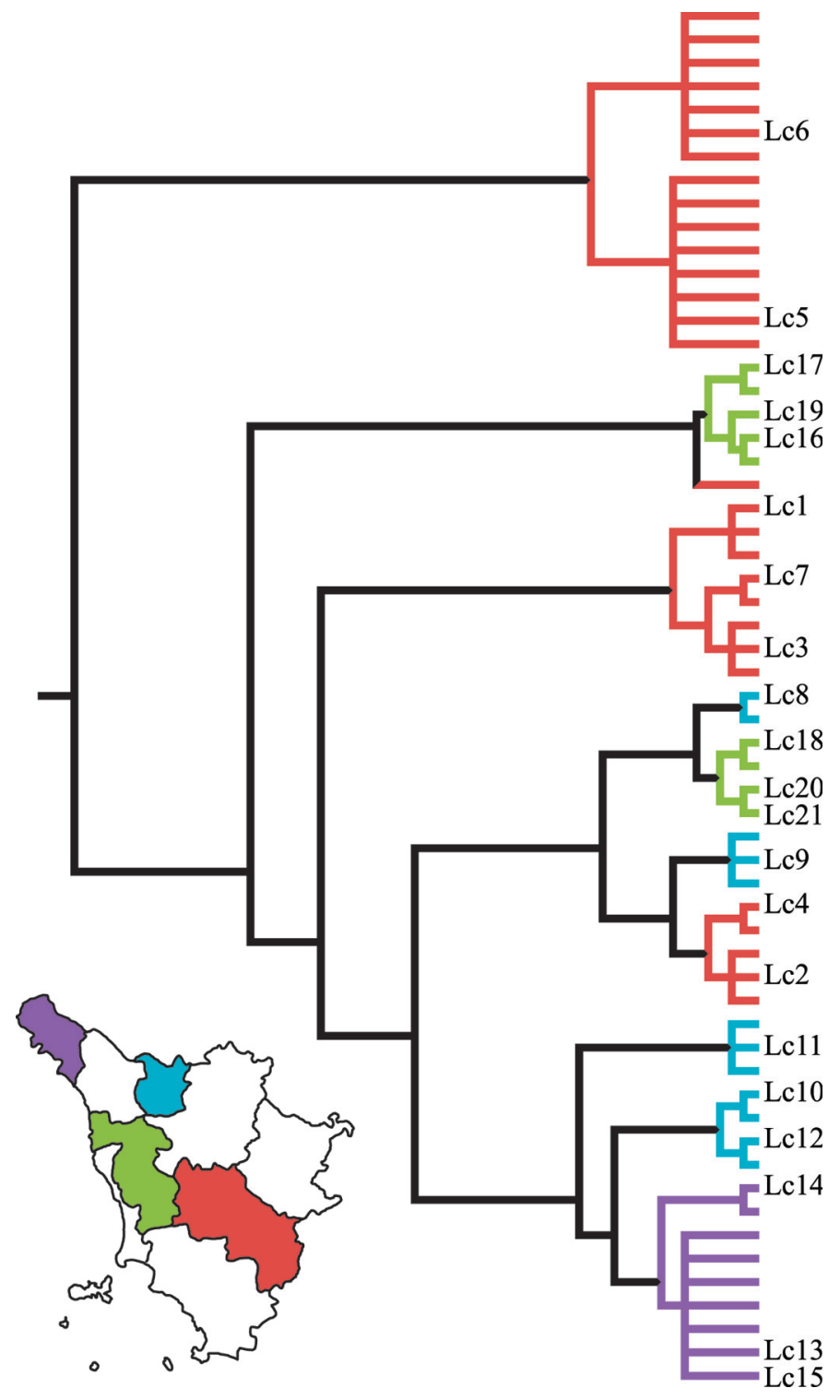

Figure 1. Cluster analysis of initial 60 isolates based on API 20 Strep kit (API System, bioMérieux, Marcy l'Etoile, France) results. Polytomies represent identical API results. The 21 labeled isolates were chosen for further genetic and phenotypic characterization. Colors of cluster groups indicate the regions of origin for those isolates. Shades (colors) of cluster groups indicate the regions of origin for those isolates. Each shade of gray (color) is reflected in the regions of a map of Tuscany: light gray (blue) for Pistoia, medium gray (green) for Pisa, dark gray (red) for Siena, and black (purple) for Massa-Carrara. Color version available in the online $\mathrm{PDF}$.

DNA (rDNA) for 30 PCR cycles and the products were sequenced via standard methods. A BLAST search of the NCBI nonredundant GenBank database (http:// blast.ncbi.nlm.nih.gov) confirmed that all of the strains belonged unequivocally to the genus Lactococcus, and subspecies of $L$. lactis were determined with $100 \%$ identity. However, isolates Lc5 and Lc6 were identified as Lactococcus raffinolactis with $99 \%$ identity. The strain identities of the 11 lactis and 10 cremoris subspecies isolates are shown in Figure 2.

Multiple protein-coding loci were then evaluated via MLST using the analytical methods employed by Rademaker et al. (2007). Primers were used for the sequence analysis of 3 housekeeping genes (atpA, pheS, and rроA) and 3 functional genes (bcaT, pepN, and pepX) selected for their conservation among available lactic acid bacteria genomes and broad distribution across the genome in unlinked locations without multiple copies. The branched-chain aminotransferase BcaT and peptidases PepN and PepX are important for development of aroma precursors and textural qualities in dairy products from metabolism of milk proteins (Yvon et al., 2000; Luoma et al., 2001). The obtained PCR products were purified and sequenced as before. Single forward sequences were trimmed, aligned, and analyzed using MEGA 5 software (Tamura et al., 2011). The L. raffinolactis isolates did not generate amplicons for some of the genes and were omitted from MLST analyses.

For each strain, a sequence type (ST) was assigned, derived from the combination of different alleles at the 7 genes. Among the 21 strains, 10 different ST were attributed. No ST were found in more than one dairy, although more than one ST was isolated from half the dairies. The number of polymorphic sites varied considerably among the 7 genes, particularly in pepX and pepN, which are involved in flavor production, followed by atpA and bcaT $(105,60,51$, and 50 polymorphic sites respectively). This variation among genes implicated in texture and flavor development highlights the importance of microbiota in cheese terroir.

The complete data set of all 7 gene sequences was then analyzed by the neighbor-joining method (Saitou and Nei, 1987), resulting in a tree reflective of the ST assigned and 2 distinct clusters of similar topology for the lactis and cremoris genotypes (Figure 2; and for each gene in Supplementary Figure S1; http://www. journalofdairyscience.org/). Results of phenotypic characterization tests are reported next to the 2 main clusters, showing several intra-cluster patterns. Trends in salt and temperature tolerance, acidification, and proteolysis clearly paralleled ST.

A major advantage of MLST is the ability to accurately compare strains from different studies provided that the same primers are used. The 21 strains from this study were compared those investigated by Rademaker et al. (2007) and Fernández et al. (2011). The comparison showed little or no overlap in ST between strains of different origin (Supplementary Figure S2; http://www.journalofdairyscience.org/), underscoring the specificity of the strains for a given location and the power of MLST to distinguish strains. 


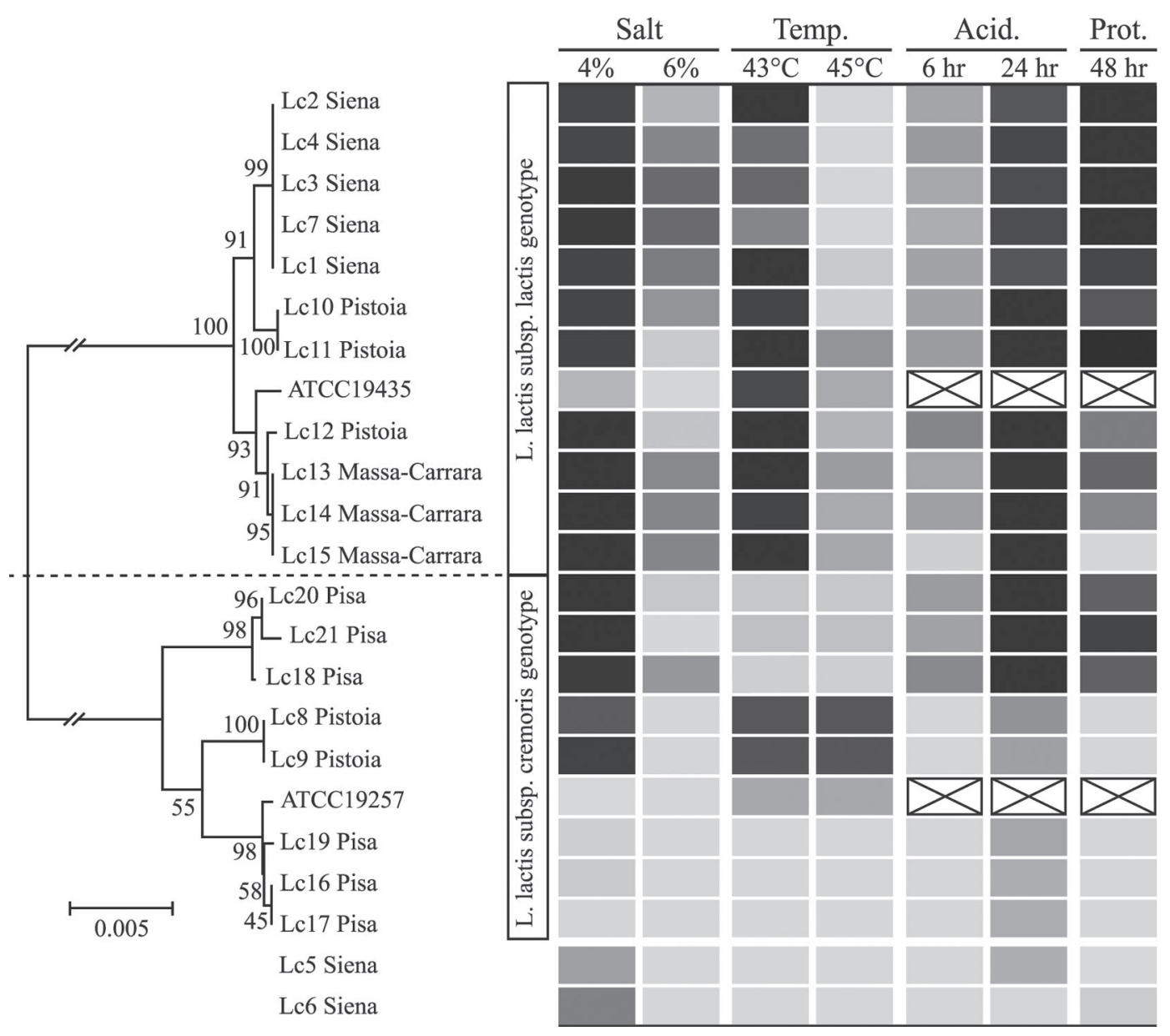

Figure 2. Neighbor-joining cluster analysis of a multilocus sequence typing (MLST) of partial sequences from the atpA, bcaT, pepN, pepX, pheS, rpoA, and 16s rRNA genes of 19 wild Lactococcus lactis strains and 2 control strains from the American Type Culture Collection (ATCC, Manassas, VA), compared with their phenotypic characteristics. Bootstrap percentages after 500 simulations are shown at the nodes. The 2 main clusters represent subspeciation, as indicated by boxes next to the tree. Isolates Lc5 and Lc6, strains of Lactococcus raffinolactis, are included below for comparison. The results of associated phenotypic tests are represented by shaded cells ranging from light gray (lowest) to black (highest). A white cell with an $\mathrm{X}$ indicates that results were not determined. Phenotypic characteristics include growth at $4 \%$ and $6 \% \mathrm{NaCl}$, growth at 43 and $45^{\circ} \mathrm{C}$, and acidification and proteolysis of milk over the indicated incubation periods.

This study has shown examples of methods used for isolation of autochthonous bacteria and characterization of the phylogenetic distribution of such organisms in different cheese-making environments. However, additional elucidation of phenotypic and technological characteristics revealed even greater diversity among strains than a purely genetic approach would allow. The information from these phenotypic and technological tests has shown differentiation beyond that of MLST, differentiating metabolic activities of isolates even with the same ST. Together, these techniques have provided a detailed estimate of regional microbial diversity in an important cheese-making organism and deliver strong evidence that the natural microbiota within Pecorino cheeses vary with their region of origin.

In conclusion, the amount of polymorphism observed via genetic analysis signifies the potency of
MLST as a tool to assess the ecology within microbial populations from different sources, particularly when complemented with relevant phenotypic analyses. Such approaches will likely have the power to discriminate between varieties and localities of cheese by correlating their autochthonous microbial populations, which could be a useful tool to preserve and explore the effect of traditional cheese-making technology. The intraspecies genetic and phenotypic diversity of the strains isolated in this study reinforces the need for a broader understanding of the populations involved in cheese production and their effects on flavor and quality. This diversity supports the conception that distinctive regional qualities of cheeses are strongly influenced by microbial ecology; however, further study will be needed to correlate the roles of these organisms with resulting sensory aspects. 


\section{ACKNOWLEDGMENTS}

This project was supported by the USDA Cooperative State Research, Education and Extension Service, Hatch project number \#ILLU-698-339. M.V.T. was supported by the Bill and Agnes Brown Fellowship, and A.L. was supported by the UIUC Research Apprenticeship Program.

\section{REFERENCES}

Alegría, A., P. Szczesny, B. Mayo, J. Bardowski, and M. Kowalczyk. 2012. Biodiversity in Oscypek, a traditional Polish cheese, determined by culture-dependent and -independent approaches. Appl. Environ. Microbiol. 78:1890-1898. http://dx.doi.org/10.1128/ AEM.06081-11.

Aquilanti, L., G. Silvestri, E. Zannini, A. Osimani, S. Santarelli, and F. Clementi. 2007. Phenotypic, genotypic and technological characterization of predominant lactic acid bacteria in Pecorino cheese from central Italy. J. Appl. Microbiol. 103:948-960. http:// dx.doi.org/10.1111/j.1365-2672.2007.03513.x.

Bergey, D. H., and J. G. Holt. 1994. Genus Lactococcus. Pages 527-558 in Bergey's Manual of Determinative Bacteriology. 9th ed. Williams \& Wilkins, Baltimore, MD.

Bilhère, E., P. M. Lucas, O. Claisse, and A. Lonvaud-Funel. 2009. Multilocus sequence typing of Oenococcus oeni: Detection of two subpopulations shaped by intergenic recombination. Appl. Environ. Microbiol. 75:1291-1300. http://dx.doi.org/10.1128/AEM.0256308.

Cai, H., B. T. Rodríguez, W. Zhang, J. R. Broadbent, and J. L. Steele. 2007. Genotypic and phenotypic characterization of Lactobacillus casei strains isolated from different ecological niches suggests frequent recombination and niche specificity. Microbiology 153:2655-2665. http://dx.doi.org/10.1099/mic.0.2007/006452-0.

Chaves-López, C., M. De Angelis, M. Martuscelli, A. Serio, A. Paparella, and G. Suzzi. 2006. Characterization of the Enterobacteriaceae isolated from an artisanal Italian ewe's cheese (Pecorino Abruzzese). J. Appl. Microbiol. 101:353-360. http://dx.doi. org/10.1111/j.1365-2672.2006.02941.x.

Cosentino, S., M. Fadda, M. Deplano, A. Mulargia, and F. Palmas. 2001. Yeasts associated with Sardinian ewe's dairy products. Int J. Food Microbiol. 69:53-58. http://dx.doi.org/10.1016/S01681605(01)00572-4.

De Angelis, M., A. Corsetti, N. Tosti, J. Rossi, M. R. Corbo, and M. Gobbetti. 2001. Characterization of non-starter lactic acid bacteria from Italian ewe cheeses based on phenotypic, genotypic, and cell wall protein analyses. Appl. Environ. Microbiol. 67:2011-2020. http://dx.doi.org/10.1128/AEM.67.5.2011-2020.2001.

de Las Rivas, B., A. Marcobal, and R. Munoz. 2004. Allelic diversity and population structure in Oenococcus oeni as determined from sequence analysis of housekeeping genes. Appl. Environ. Microbiol. 70:7210-7219. http://dx.doi.org/10.1128/AEM.70.12.72107219.2004

Diancourt, L., V. Passet, C. Chervaux, P. Garault, T. Smokvina, and S. Brisse. 2007. Multilocus sequence typing of Lactobacillus casei reveals a clonal population structure with low levels of homologous recombination. Appl. Environ. Microbiol. 73:6601-6611. http:// dx.doi.org/10.1128/AEM.01095-07.

Durlu-Ozkaya, F., V. Xanthopoulos, N. Tunail, and E. LitopoulouTzanetaki. 2001. Technologically important properties of lactic acid bacteria isolates from Beyaz cheese made from raw ewes' milk. J. Appl. Microbiol. 91:861-870. http://dx.doi.org/10.1046/j.13652672.2001.01448.x.

Fernández, E., A. Alegría, S. Delgado, M. C. Martín, and B. Mayo. 2011. Comparative phenotypic and molecular genetic profiling of wild Lactococcus lactis ssp. lactis strains of the L. lactis ssp. lactis and L. lactis ssp. cremoris genotypes, isolated from starter-free cheeses made of raw milk. Appl. Environ. Microbiol. 77:53245335. http://dx.doi.org/10.1128/AEM.02991-10.

Feutry, F., M. Oneca, F. Berthier, and P. Torre. 2012. Biodiversity and growth dynamics of lactic acid bacteria in artisanal PDO Ossau-Iraty cheeses made from raw ewe's milk with different starters. Food Microbiol. 29:33-42. http://dx.doi.org/10.1016/j. fm.2011.08.011.

Gardini, F., R. Tofalo, N. Belletti, L. Iucci, G. Suzzi, S. Torriani, M. E. Guerzoni, and R. Lanciotti. 2006. Characterization of yeasts involved in the ripening of Pecorino Crotonese cheese. Food Microbiol. 23:641-648. http://dx.doi.org/10.1016/j.fm.2005.12.005.

Giammanco, G. M., A. Pepe, A. Aleo, V. D'Agostino, S. Milone, and C. Mammina. 2011. Microbiological quality of Pecorino Siciliano "primosale" cheese on retail sale in the street markets of Palermo, Italy. New Microbiol. 34:179-185.

IDF. 1988. Milk and Milk Products. Preparation of Samples and Dilutions for Microbiology Examination. International Dairy Federation, Brussels, Belgium.

Luoma, S., K. Peltoniemi, V. Joutsjoki, T. Rantanen, M. Tamminen, I. Heikkinen, and A. Palva. 2001. Expression of six peptidases from Lactobacillus helveticus in Lactococcus lactis. Appl. Environ. Microbiol. 67:1232-1238. http://dx.doi.org/10.1128/AEM.67.3.12321238.2001.

Maddison, W. P., and D. R. Maddison. 2011. Mesquite: A modular system for evolutionary analysis. http://mesquiteproject.org.

Mannu, L., and A. Paba. 2002. Genetic diversity of lactococci and enterococci isolated from home-made Pecorino Sardo ewes' milk cheese. J. Appl. Microbiol. 92:55-62. http://dx.doi.org/10.1046/ j.1365-2672.2002.01489.x.

Medina, R., M. Katz, S. Gonzalez, and G. Oliver. 2001. Characterization of the lactic acid bacteria in ewe's milk and cheese from northwest Argentina. J. Food Prot. 64:559-563.

Palmer, C., E. M. Bik, M. B. Eisen, P. B. Eckburg, T. R. Sana, P. K. Wolber, D. A. Relman, and P. O. Brown. 2006. Rapid quantitative profiling of complex microbial populations. Nucleic Acids Res. 34:e5. http://dx.doi.org/10.1093/nar/gnj007.

Palmquist, D. L., A. D. Beaulieu, and D. M. Barbano. 1993. Feed and animal factors influencing milk fat composition. J. Dairy Sci. 76:1753-1771.

Quigley, L., O. O'Sullivan, T. P. Beresford, R. P. Ross, G. F. Fitzgerald, and P. D. Cotter. 2012. High-throughput sequencing for detection of subpopulations of bacteria not previously associated with artisanal cheeses. Appl. Environ. Microbiol. 78:5717-5723. http://dx.doi.org/10.1128/AEM.00918-12.

Rademaker, J. L. W., H. Herbet, M. J. C. Starrenburg, S. M. Naser, D. Gevers, W. J. Kelly, J. Hugenholtz, J. Swings, and J. E. T. van Hylckama Vlieg. 2007. Diversity analysis of dairy and nondairy Lactococcus lactis isolates, using a novel multilocus sequence analysis scheme and (GTG)5-PCR fingerprinting. Appl. Environ. Microbiol. 73:7128-7137. http://dx.doi.org/10.1128/AEM.01017-07.

Randazzo, C. L., I. Pitino, S. De Luca, G. O. Scifò, and C. Caggia 2008. Effect of wild strains used as starter cultures and adjunct cultures on the volatile compounds of the Pecorino Siciliano cheese. Int. J. Food Microbiol. 122:269-278. http://dx.doi.org/10.1016/j. ijfoodmicro.2007.12.005.

Randazzo, C. L., E. E. Vaughan, and C. Caggia. 2006. Artisanal and experimental Pecorino Siciliano cheese: Microbial dynamics during manufacture assessed by culturing and PCR-DGGE analyses. Int J. Food Microbiol. 109:1-8. http://dx.doi.org/10.1016/j.ijfoodmicro.2005.11.002

Saitou, N., and M. Nei. 1987. The neighbor-joining method: A new method for reconstructing phylogenetic trees. Mol. Biol. Evol. 4:406-425.

Smit, G., B. A. Smit, and W. J. M. Engels. 2005. Flavour formation by lactic acid bacteria and biochemical flavour profiling of cheese products. FEMS Microbiol. Rev. 29:591-610. http://dx.doi. org/10.1016/j.femsre.2005.04.002.

Tamura, K., D. Peterson, N. Peterson, G. Stecher, M. Nei, and S. Kumar. 2011. MEGA5: Molecular evolutionary genetics analysis using maximum likelihood, evolutionary distance, and maximum 
parsimony methods. Mol. Biol. Evol. 28:2731-2739. http:// dx.doi.org/10.1093/molbev/msr121.

Tanganurat, W., B. Quinquis, V. Leelawatcharamas, and A. Bolotin. 2009. Genotypic and phenotypic characterization of Lactobacillus plantarum strains isolated from Thai fermented fruits and vegetables. J. Basic Microbiol. 49:377-385. http://dx.doi.org/10.1002/ jobm. 200800185

Turchi, B., R. Nuvoloni, F. Fratini, F. Pedonese, V. V. Ebani, and D. Cerri. 2011. Caciotta della Garfagnana cheese: Selection and eval- uation of autochthonous mesophilic lactic acid bacteria as starter cultures. Ital. J. Anim. Sci. 10: http://dx.doi.org/10.4081/ ijas.2011.e22.

Yvon, M., E. Chambellon, A. Bolotin, and F. Roudot-Algaron. 2000. Characterization and role of the branched-chain aminotransferase (BcaT) isolated from Lactococcus lactis ssp. cremoris NCDO 763. Appl. Environ. Microbiol. 66:571-577. 